\title{
A Model of Formative Assessment in Music Education
}

\author{
By Urban Kordes* \\ Barbara Sicherl Kafol ${ }^{\dagger}$ \\ Ada Holcar Brunauer
}

\begin{abstract}
Qualitative research has provided insight into how students experience and perceive the learning process in music. A model of learning, teaching, assessment and evaluation has been researched and reconstructed together with students. As a basic investigative approach the method of action research has been used. Two action cycles were planned and executed. Findings of the study in which students were given instruction with an emphasis on the development of metacognitive strategies or developing proactive and selfregulatory attitudes to learning, evaluation and assessment, broaden understanding of how to integrate assessment and evaluation into the learning process, and monitor all processes of music learning.
\end{abstract}

\section{Introduction}

Bamford points out that assessment of pupils' knowledge should be as creative as possible. Methods of assessment and evaluation should take into account various kinds of learning which enable pupils to express themselves, create and evaluate in arts education, including music education (Bamford, 2009). Given the complex nature of learning responding, which in music includes learning processes and objectives in the affective, psychomotor and cognitive domains, it is necessary to consider all three areas when establishing criteria for assessment and evaluation in music education (Sicherl-Kafol, 1997).

Standardized national tests still represent a great problem for teaching (Bresler, 2010), as many teachers teach for the tests, even though they are aware of the fact that those tests do not provide authentic feedback on pupils' musical knowledge. Authentic evaluation in music education should be based on the most important (rather than the most convenient) dimensions of musical knowing, i.e. on the processes and achievements of musical learning in the areas of performing, listening and creating which include holistic learning response (affective, psychomotor and cognitive) and represent the basis for assessment and evaluation criteria in music education (Sicherl-Kafol, 2004).

\footnotetext{
*Associate Professor, University of Ljubljana, Slovenia.

${ }^{\dagger}$ Associate Professor, University of Ljubljana, Slovenia.

${ }^{\star}$ Senior Consultant, National Education Institute Slovenia, Slovenia.
} 
This means process oriented assessment with flexible methods of evaluating musical achievements instead of the mere use of standard aptitude and knowledge tests, as "our tests are meant to measure what is least essential in the arts" (Aróstegui, 2003, str. 112). In her book Beyond Testing (Gipps, 1994a), Caroline Gipps defines this as a shift from a culture of tests and interrogations to a culture of assessment and evaluation at different stages of learning in its various forms.

Assessment for learning (Daniel, 2004) attributes a great importance also to self-assessment and peer assessment that have a very positive impact on learning. Research show (Bloom in Poole, 2004) that pupils involved in such assessment developed their learning skills, critical thinking, evaluation skills, improved their self-confidence and their understanding of assessment procedures. Also, their wish to participate and assume responsibility for their learning increased, while the quality of their feedback kept improving. Bloom and Poole (2004) report, that involving pupils into peer assessment made it possible to harmonise their expectations with the reality; to them, assessment was no longer something mysterious, alienated, something that others arrange for them. Pupils understood they were offered a different method of learning and insight into the process of their own musical development.

\section{Research Objectives}

Based on the above mentioned problems this study aimed at contributing to the development of the theory of music learning, teaching, assessment and evaluation and defining the current state and possibilities for formative knowledge assessment that would enable assessment and evaluation of all musical learning processes and achievements. We were particularly interested in:

1) How do pupils experience the processes of learning, teaching and formative knowledge assessment in performing, creating, listening to music and evaluating musical works?

2) How to include pupils in the formative knowledge assessment process in music education and enhance their abilities of managing their own learning?

3) How to use formative assessment of music learning processes and achievements to encourage pupils to engage in reflection, selfassessment and peer assessment?

4) How to assess and evaluate musical learning processes and achievements within the formative assessment model? 


\section{Methodology}

\section{Research Method}

Since the aim of this study was to explore and reconstruct, together with pupils, the formative assessment model in the context of various constructed situations, we chose the qualitative research method. As the basic research approach we used the action research method, as we did not only describe and explain the situation, but we also changed it and showed the process of changing (Phelps in Hase, 2002). The action research stage was followed by the analysis of results in the form of multiple case study. Since the problem was of distinctively qualitative nature, the method of work was hermeneutical, which means making adjustments to the research questions and research approaches on the basis of the dynamics of working with pupils. We planned and carried out two action cycles. During and at the end of each action cycle pupils were encouraged to write down reflections into their development workbooks ${ }^{1}$. These reflections contributed to a more objective evaluation of holistic assessment and evaluation processes in music education. At the beginning and at the end of each action cycle, a group interview was carried out in a focus group. As this was not a statistically relevant, quantitative sample, action research was used to establish optimisation of the learning model.

\section{Participants}

The selection of participants was intentional and occasional. In this exercise of action research and verification of the model's efficiency, one of the authors assumed the role of music education teacher in grade 8 (11 pupils) of the Danila Kumar International School, Ljubljana.

Materials for Analysis

Throughout the year, students used a development workbook (IBO Arts Guide, 2008) which provided encouragement for directing their own learning, exchanging feedback and engage in self-assessment. The workbook enabled students to develop critical thinking, monitor the process of attaining musical achievements and write down reflections. In the following text the abbreviation DWB is used for development workbook. In the analysis, DWBs are marked with numbers 1 to 11 . The teacher kept a research diary where she recorded various notes, findings, considerations and reflections about the lessons and discussions with pupils.

Group interviews with pupils in the focus group were recorded and later transcribed and translated from English into Slovenian. The transcription was divided into units of meaning and openly coded (analysed, studied, compared, and categorized). For coding we used the inductive approach. Each unit is marked with the consecutive number of the focus group interview (e.g. FG1), followed by information about whether the statement was made by a girl or by a boy (F - girl, M - boy) and the consecutive number of the unit (e.g. U1).

\footnotetext{
${ }^{1}$ Development workbooks are presented in the following chapters.
} 


\section{Procedure}

The study was carried out in two stages - an action stage and a comparative stage.

\section{The Action Stage}

The pilot trial of the model was accompanied by action research. Action research enabled us to inquire and solve the problems we identified in the course of the study. The planned cycles lasted for one semester each. At the beginning we defined the action steps, based on previous research mentioned in the theoretical introduction. With the first cycle concluded, we carried out an evaluation. It included qualitative analysis of the above mentioned materials (development workbooks, research diary, and focus group interview). For the analysis we used methods of qualitative coding (attribution of concepts to empirical descriptions, distributing related concepts into categories, axial coding). Based on this, the action measures for the next cycle were established. During the first cycle the teaching was focused on development of selfassessment, while in the second cycle the focus was on developing selfregulatory learning. Based on this, a (multiple) case study was carried out with an attempt of developing a grounded theory.

\section{Comparative Stage}

After the action stage was concluded, the comparative stage followed. During this stage comparison of the analyses of pedagogical process and cycles outcomes was carried out. The work dynamics of both cycles were analysed along the timeline. Observation of qualitative differences between the processes of the two cycles was carried out, with emphasis on the search for answers to the research questions.

\section{Course of Research}

The purpose of the first conversation in focus groups at the beginning of the first action cycle was to get information about pupils' views and understanding of learning, teaching, assessment and evaluation. We were interested in what music education lessons should be like in order for them to gladly attend them and to see assessment as support to their learning. We analysed the transcriptions of this conversation and used the findings of this analysis in planning of the first action cycle/learning unit during which pupils created music on a given text. At the beginning of the learning unit pupils were given written instructions on individual learning steps that led them through the first learning unit from selection or creation of a text to creation of rhythmical and melodic contents and formation of a simple harmony. During the process of creating musical contents the teacher was asking them questions aimed at directing them to plan, monitor and self-evaluate their own work, and stimulating self-regulation of their learning.

The findings of the analysis of the development workbooks, diary and transcription of the second focus group interview carried out at the end of the first action cycle, were used in planning of the second action cycle/learning 
unit during which students created music in the impressionist style. Again, pupils were first given written instructions on individual learning steps that led them through the second learning cycle from exploring the characteristics of the impressionist music and its composers to creating musical contents, using impressionistic elements (pentatonic and whole-tone scales, tone painting, chords with chromatic elements, harmonic vertical). In the second learning cycle, self-regulation of learning was given an even stronger emphasis. Besides the questions that encouraged students to think about their own learning, they also received working sheets which helped them make their own work plans. The second learning cycle concluded with the performance of pupils' compositions in impressionist style.

\section{Inclusion of Pupils in the Formative Assessment Model in Music Education}

Analysis of the First Focus Group Interview

The analysis of the first focus group interview showed that pupils expressed rather negative views regarding assessment and evaluation. Those negative views were associated with numeric grades as a mean of external motivation that only serves as such when pupils are not interested in a certain topic or subject, or towards the end of a school year, when studying can contribute to improving some grades. Their view was that assessment is not fair, because in the tests, which are assessed, they can only show a small part of their knowledge; they also felt that teachers often say what they are going to assess but then they do not stick to that. Therefore, pupils believed that numeric grades do not reflect their knowledge. Privileged pupils also pointed out that some teachers favour some pupils, so they will give them a higher grade that they deserve, which they were rather discontent about.

All of that is also reflected in their statements:

In the tests you can only show a part of your knowledge (FG 1/U 51). For example, sometimes I do very little at a certain subject, but I get an excellent grade anyway, because the teacher likes me (FG 1/U 53).

Grades are a huge motivator, but they will not get you a long way, as far as knowledge is concerned. You only study as much as it is necessary to get a certain grade. However, if you're interested in something, then you will go much further (FG 1/U 55).

Descriptive assessments are much more appropriate than numeric grades, because they tell us much more (FG 1/U 58).

Analysis of the Development Workbooks after the First Action Research Cycle The music education teacher took into consideration the wishes expressed 
by pupils in the first focus group interview; besides, she also tried to include pupils in the development of performance criteria, self-assessment and peer assessment processes and to stimulate their self-regulative attitude towards learning.

Development workbooks analysis showed that most pupils were enthusiastic about the fact that they could create music and express their thoughts and feelings. They dedicated a lot of attention to the findings attained in group work which has its own rules and limitations, but at the same time enables infinite breadth, when several minds work together.

Here are a few examples from the development workbooks:

The most precious to me were the feelings that emerged when I was composing and listening to the music I had created (DWB 1).

For me it was precious to learn how a group works and how unlimited the possibilities are when you are creating music (DWB $5)$.

As part of their reflection at the end of each action cycle, pupils drew diagrams in which they expressed:

- the interest they showed in learning/work,

- the energy of the group/individual invested in learning/work, and

- knowledge acquired in an individual learning cycle.

Diagram 1. The Average of all Pupils, Areas: Interest in Learning, Group or Individual Energy, Knowledge, in the Period October 2010 to February 2011

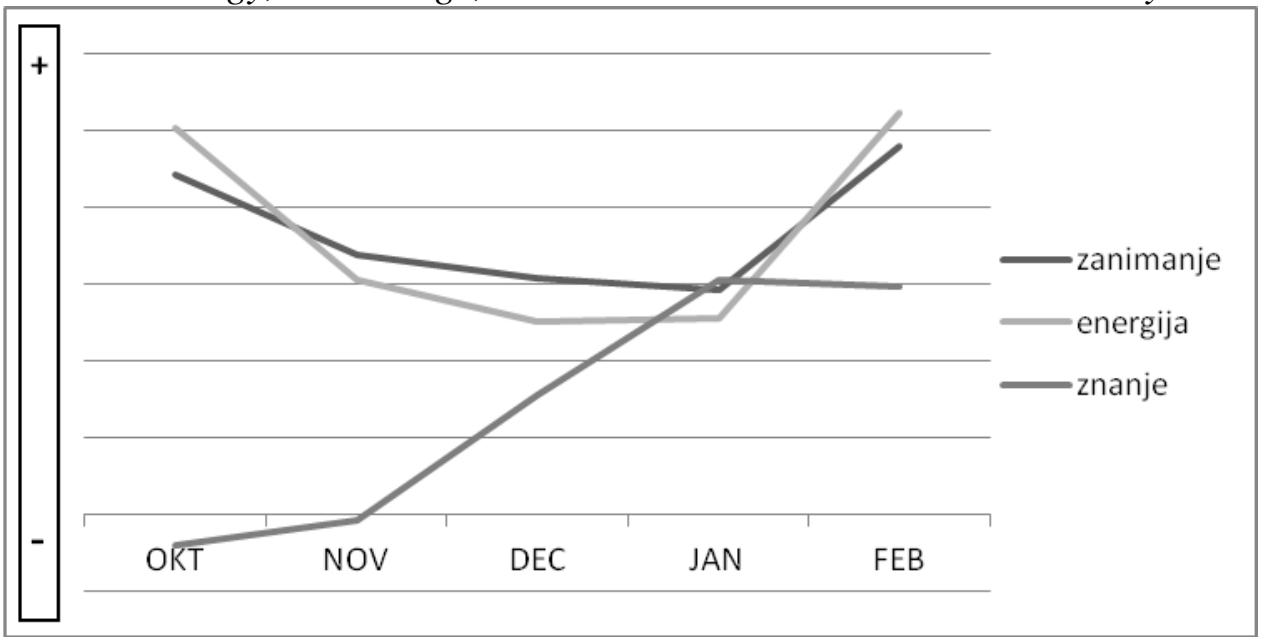

The fact that the interest and energy started decreasing soon after the beginning of the first action cycle, but then started rising in mid-January, could be attributed to the lengthy first learning unit, which lasted five month. The drop in interest and energy can also be attributed to the fact that in group work, pupils were for the first time faced with a creative process in a way that required them to work independently and assume responsibility. To do so, they 
had to learn, discover and acquire new musical knowledge every step of the way.

This is reflected in the statements they put down into their DWBs:

...usually I cannot work well if I am in the same group with Lara. However, I have to admit that this time we went on really well. Not so much at the very beginning, but then it got better and better... (DWB 6).

In our group, we first tried to create a melody without any text. We thought this would be the easiest way. But we progressed very slowly. Then the teacher advised us to write the text first. We wrote a love poem and then we composed music to it. This proved to be a much more effective way (DWB 2).

\section{Analysis of the Second Focus Group Interview}

In the second focus group interview, pupils drew from the experience acquired in the first learning unit. The analysis of the second focus group discussion showed that pupils attributed the highest satisfaction to learning when they were creating musical contents and at the same time expressed enthusiasm about the discovery that learning can be a delightful and unforgettable experience. Their enthusiasm about creating music was quite surprising, since this was an area that was not even touched upon by pupils during the first focus group discussion, even though it is an important musical activity. Their participation in a creative process brought pupils entirely new findings and discoveries about learning. Also, it turned out that pupils did not miss numeric grades which, as it was agreed in the first focus group discussion, were replaced by descriptive assessments. They expressed great satisfaction with descriptive assessments that told them which areas they are successful in and what should be further improved, while at the same time contributing to a faster progress.

Pupils said:

Usually teachers say: 'now you are going to create' and then they limit us very much and determine every detail and choose for us what to do. So, there is not much left of creativity, and in particular of creating something new (FG 2/U 43).

It was exciting to receive comments from our classmates who told us what to improve (FG 2/U 61).

A lot of feedback and descriptive assessments, by the pupils and by the teacher, were given orally. In giving feedback the teacher tried to focus as much as possible on individual aspects of the tasks ("what, how and why") and 
on suggestions as to how these aspects could be improved. Feedback information was precise and specific, stimulating pupils to think about and look for improvements of their work and tasks.

Analysis of Development Workbooks after the Second Action Research Cycle

In the second action cycle, the teacher took into account the wishes pupils expressed in the second focus group discussion. At the beginning of the second unit, pupils participated in defining performance criteria. With the help of working sheets and questions posed by the teacher at different stages of the learning unit, pupils planned their work, were involved in self-evaluation and learned to take on responsibility for their learning.

Analysis of development workbooks showed that help by schoolmates, work plan that they followed and their own motivation represented the offered them the most support in composing music in impressionist style. They were enthusiastic about the fact that they learned a lot about impressionism, the scales that were used in this period; they discovered new ways of playing instruments and composed music in impressionist style. They wrote down in their workbooks that the most important thing in the second learning unit was creating musical contents and performing the compositions they created.

Diagram 2. The Average of all Pupils, Areas: Interest in Learning, Group Energy, Knowledge in the Period March 2011 to May 2011

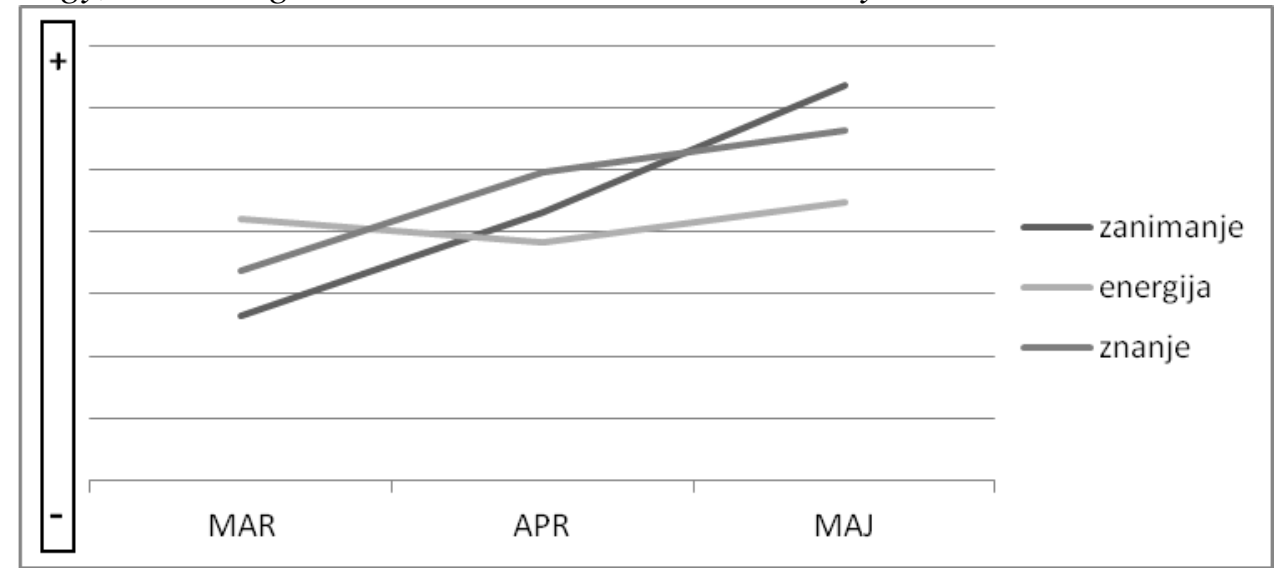

At the end of the second learning unit, again, pupils drew diagrams as part of their reflections. In the analysis of the work dynamics diagrams in the second learning unit (which lasted from March to May 2012) we wanted to find out the pupils' interest in learning/work, the energy shown and the knowledge acquired in the second learning unit. Their reflections expressed with diagrams, show a slight drop in energy and a considerable raise in knowledge and interest throughout the second learning unit, which could be attributed to the fact that by then pupils had acquired the metacognitive processes and were greatly involved in self-regulation of learning. They planned their work and considered what else should be done in order to achieve the best results possible. The big rise in interest in the second learning unit is probably also the result of the fact that the second learning unit was much 
shorter than the first one and, in terms of the time line, defined more into details.

\section{Analysis of the Third Focus Group Interview}

The analysis of the third focus group interview showed that pupils started becoming aware of the processes of creating musical contents, which was one of the planned steps for the second action cycle; they pointed out the importance of monitoring one's own progress - the steps of writing one's own composition, compared their work to the work of composers and realised that creating something new is a very demanding task that requires a lot of perseverance. They had become more and more aware of the importance of monitoring one's own progress and looking for the optimal paths for proper development, they were discovering what worked and what did not, for which their own findings and discoveries were the most important for them. Pupils considered the steps that needed to be taken to reach the goal, whether they were necessary or if they should choose a different way. They became more and more involved in self-regulation of learning and were consciously changing the learning process. They attached great importance to the fact that they were gaining experience and planning work on their own and took on responsibility for their own learning. In their opinion this stimulated the development of self-regulation of learning and consequently enabled better musical achievements. Raising awareness of metacognitive processes and selfregulation of learning made realise the majority of pupils that learning is much more than taking in new contents. They found out that learning is about the processes that are going to be very useful in their lives, such as feedback, group work, deeper understanding of music, learning for life and expressing through music in order to relax or put forth the inner feelings.

\section{Research Findings}

In pupils' opinion, the biggest sense of learning is in creating and performing music, because these activities enable them to express their emotions and experiences.

Pupils pointed out the unique experience of creative expression, made possible by music, as the most important area of their work and the importance of being part of the entire process of making a musical product (from its creation to performance), which they connected with experience that will be useful later on in their lives.

Inclusion of pupils in the formation of a formative assessment model in music education contributed to the fact that pupils changed their opinions regarding assessment and evaluation. 
In our study we were particularly interested in pupils' attitudes towards assessment and evaluation. In the first focus group interview, pupils defined assessment and evaluation as a rather negative area and indicated, they would like to receive feedback on their work in the form of descriptive assessment more often, which the teacher fulfilled throughout the course of the study. In the second and third focus group interview, pupils expressed enthusiasm about descriptive assessments. They saw assessment and evaluation as the part of the learning process which directed their thinking process and enabled reconstruction, comparison, exchange and peer evaluation of ideas.

This is shown by the following statement:

Grades are a huge motivator, but they will not get you a long way, as far as knowledge is concerned. You only study as much as it is necessary to get a certain grade. However, if you're interested in something, then you will go much further (FG 1/E $55)$.

The research results speak in favour of descriptive assessment. However, it needs to be pointed out that pupils received descriptive assessment of high quality, based on holistic approach and authentic methods of assessment and evaluation of musical processes and achievements. Assessment and evaluation was part of every stage of teaching from planning to implementation, and it also involved a different lesson planning - a shift to creating "didactic situations" in which the teacher used tasks, conversation and questions to encourage pupils to learn. The teacher's role changed from passing on knowledge to encouraging dialogue.

\section{Peer-assessment and self-regulation of learning are two areas which pupils will be able to use latter in their lives and they make learning meaningful.}

The analysis of the second group interview showed the importance of peer-assessment of musical achievements which was perceived by pupils as adding sense to their learning. Their positive views of peer-assessment were attributed to the fact that it was not about judging, but rather about helping with advice what could be improved, upgraded or changed. At the same time they believed that they would be able to use the evaluation skills they developed in school as well as later in their lives.

This is expressed by the following words:

Sincere evaluation of our work, without judging each other, was the greatest experience that I will carry on into my life (FG3/F/U80).

It meant a lot to them that they could create musical contents in groups, that the teacher took into account their interests and wishes, but the most 
important thing was that they recognized areas of learning which they will be able to use later on in their lives. The perception of these areas had to be additionally stimulated from time to time with questions that made them think and look for broader applicability of school work.

In the third focus group conversation pupils compared the first and the second action cycle. They pointed out that their own experiences and findings acquired in both cycles were the most precious to them. They emphasised the importance of the experience from the first cycle when they wanted to dedicate the creation of musical contents as much time as they considered necessary. This led them to realise that they needed a quite accurate work plan defining exactly who does what, until when and how.

In their statements, pupils attached considerable weight to their own experiences. The complex dimensions of the effects of formative assessment showed when pupils were considering the awareness of their own thinking processes, compared the first and the second action cycles and reflected their own development in the area of self-regulation.

\section{Conclusion}

The dynamic nature of modern forms of learning and teaching requires holistic methods and forms of assessment and evaluation that become part of the learning process and, in the form of feedback information, help pupils in their work and progress. Instead of focusing merely on the learning results, assessment and evaluation contribute to the creation of quality conditions for learning. Formative assessment includes gathering data about a pupil as a whole and the use of various information sources. The learning process has to show pupils the learning paths as sensible, leading to goals worth working for. Such learning paths offer pupils opportunities to create and perform music and encourage them to pick areas that they are interested in and explore them. In the learning process, pupils come across challenges that arouse in them interest and the wish to explore, discover and make further progress. In doing so, descriptive assessments can be helpful, as they enable faster progress ad a more in depth learning. Pupils become more and more aware of how important it is to follow their own progress and to look for optimum ways for their own development, they learn what works and what does not, and think about learning steps that need to be taken on the way to the final goal.

The findings of the study in which pupils were subject to formative assessment of music education processes and achievements, showed that:

- Pupils associate positive attitudes to assessment especially with descriptive assessments and peer-assessment.

- Quality feedback information contributes to improvement of learning achievements and independent learning, helps develop 
metaknowledge, promotes self-regulation, self-assessment and further learning.

- Experiencing and discovering knowledge on your own, with space given to researching, team work, setting goals and taking into account a pupil's interests gives sense to learning.

- Pupils are more motivated by learning which is connected to real life and which they can see sense in. However, they need to be steered (e.g. with questions) in the direction of perceiving these connections.

The focus is on different methods of assessment and evaluation (Black and Wiliam, 1998; Colwell 2006; Fautley, 2010; James, 2006; Marentič Požarnik, 2004; Razdevšek Pučko, 2004; Torrance 2007) that enable pupils to participate in setting the performance criteria, planning various ways of presenting the acquired knowledge, and to be involved in the processes of self-assessment, self-evaluation and peer-assessment. This kind of assessment and evaluation are seen by pupils as part of the learning process which helps them learn and attain better musical achievements. Thus, pupils become co-shapers of the educational process and its results, which motivate them for work and equips them with skills and experience they can carry on into their lives, while at the same time contributing to a positive attitude towards assessment and evaluation.

The findings of this study represent a challenge of establishing a new assessment and evaluation paradigm based on pupils' participation in the processes of monitoring knowledge and assuming a greater responsibility for their own learning. Pupils become co-creators of the learning process and gain experience that are important for further learning and in other areas of life

\section{References}

Aróstegui, J. L. 2003. On the nature of knowledge: what we want and what we get with measurement in music education. International Journal of Music Education, $40,100-115$.

Bamford, A. 2009. Arts and Cultural Education in Iceland. Icelandic Ministry For Education and Culture.

Black, P. and Wiliam, D. 1998. Assessment and Classroom learning. Assessment in Education, 5(1), 7-73.

Bloom, D. and Poole, K. 2004. Peer assessment of tertiary music performance: Opportunities for understanding performance assessment and performing through experience and self-reflection. British Journal of Music Education, 21(1), 111125.

Bresler, L. 2010. Integration of music into academic disciplines: A manifestation of educational enterpreneurship, Glasba $v$ šoli in vrtcu, 15(1), 3-17.

Colwell, R. 2006. Assessment's potential in music education. In R. Colwell, (Ed.), MENC handbook on research on music teaching and learning, 199-270. Reston, New York: Oxford University Press, Inc.

Daniel, R. 2004. Peer assessment in musical performance: The development, trial and 
evaluation of a methodology for the Australian tertiary environment. British Journal of Music Education, 21(1), 89-110.

Fautley, M. 2010. Assessment in Music Education. Oxford: Oxford University Press.

IBO (International Baccalaureate Organization). 2008. IBO Arts Guide 2008. Cardiff: IBO Peterson House.

James, M. 2006. Assessment, Teaching and Theories of Learning. V Gardner, J. (ur.). Assessment and Learning. London: SAGE Publications Ltd.

Komljanc, N. 2008. Formativno spremljanje učenja. In M. T. Škraba (Ed.), Didaktika ocenjevanja znanja. Ljubljana: Zavod RS za šolstvo.

Marentič Požarnik, B. 2004. Kako bolje uravnavati mogočen vpliv preverjanja in ocenjevanja. Sodobna pedagogika, 55(1), 8-22.

Phelps, R. and Hase, S. 2002. Complexity and Action Research: exploring the theoretical and methodological connections. Education Action Research, 10(3), 507-524.

Razdevšek Pučko, C. 2004. »Formativno preverjanje znanja in vloga povratne informacije«. Sodobna pedagogika, 55(1), 126-139.

Sicherl Kafol, B. 1997. Opisno ocenjevanje pri glasbeni vzgoji na začetni stopnji osnovne šole. In B. Oblak (Ed.), Glasbeno-pedagoški zbornik. Ljubljana: DAN d. d.

Sicherl Kafol, B. 2004. Preverjanje in ocenjevanje pri glasbeni vzgoji. Domžale: Izolit.

Torrance, H. 2007 Assessment as learning? How the use of explicit learning objectives, assessment criteria and feedback in post-secondary education and training can come to dominate learning. Assessment in Education, 14(3), 281294. 
